Article

\title{
Effects of Overproduction of Rubisco Activase on Rubisco Content in Transgenic Rice Grown at Different $\mathbf{N}$ Levels
}

\author{
Mao Suganami ${ }^{1}$, Yuji Suzuki ${ }^{2}{ }^{\mathbb{D}}$, Eri Kondo ${ }^{1}$, Shinji Nishida ${ }^{1}$, So Konno ${ }^{1}$ \\ and Amane Makino 1,*(D) \\ 1 Graduate School of Agricultural Science, Tohoku University, 468-1 Aramaki-Aoba, Aoba-ku, \\ Sendai 980-8572, Japan; mao.suganami.p7@dc.tohoku.ac.jp (M.S.); eri.kondo.c2@tohoku.ac.jp (E.K.); \\ shinjinishida1@gmail.com (S.N.); sou.konno.t4@dc.tohoku.ac.jp (S.K.) \\ 2 Faculty of Agriculture, Iwate University, 3-18-8 Ueda, Morioka, Iwate 020-8550, Japan; ysuzuki@iwate-u.ac.jp \\ * Correspondence: amanemakino@tohoku.ac.jp; Tel.: +81-22-757-4287
}

Received: 16 January 2020; Accepted: 26 February 2020; Published: 27 February 2020

check for updates

\begin{abstract}
It has been reported that overproduction of Rubisco activase (RCA) in rice (Oryza sativa L.) decreased Rubisco content, resulting in declining photosynthesis. We examined the effects of RCA levels on Rubisco content using transgenic rice with overexpressed or suppressed $R C A$ under the control of different promoters of the $R C A$ and Rubisco small subunit $(R B C S)$ genes. All plants were grown hydroponically with different $\mathrm{N}$ concentrations $(0.5,2.0$ and $8.0 \mathrm{mM}-\mathrm{N})$. In RCA overproduced plants with $>2$-fold RCA content (RCA-HI lines), a 10\%-20\% decrease in Rubisco content was observed at 0.5 and $2.0 \mathrm{mM}-\mathrm{N}$. In contrast, at $8.0 \mathrm{mM}-\mathrm{N}$, Rubisco content did not change in RCA-HI lines. Conversely, in plants with 50\%-60\% increased RCA content (RCA-MI lines), Rubisco levels remained unchanged, regardless of $\mathrm{N}$ concentration. Such effects on Rubisco content were independent of the promoter that was used. In plants with $R C A$ suppression to $<10 \%$ of the wild-type RCA content, Rubisco levels were increased at $0.5 \mathrm{mM}-\mathrm{N}$, but were unchanged at 2.0 and $8.0 \mathrm{mM}-\mathrm{N}$. Thus, the effects of the changes in RCA levels on Rubisco content depended on N supply. Moreover, RCA overproduction was feasible without a decrease in Rubisco content, depending on the degree of RCA production.
\end{abstract}

Keywords: Rubisco; Rubisco activase; Rubisco activation; photosynthesis improvement; nitrogen; transgenic rice

\section{Introduction}

Ribulose-1,5-bisphosphate carboxylase/oxygenase (Rubisco), the enzyme that catalyzes the two competing reactions of $\mathrm{CO}_{2}$ fixation in photosynthesis and production of 2-phosphoglycolate in the photorespiratory pathway, is a rate-limiting factor for light-saturated photosynthesis at the present atmospheric air conditions [1,2]. Thus, Rubisco has been considered to be one of the most important targets for improving photosynthesis capacity (e.g., [3-5]). The activity of Rubisco is inhibited by the binding of sugar phosphates-ribulose-1,5-bisphosphate (RuBP, a substrate of Rubisco), carboxyarabinitol 1-phosphate (CA1P, a nocturnal metabolite), and xylulose-1,5-bisphosphate (XuBP) and 2,3-pentodiulose-1,5-bisphosphate (PDBP), which are "misfire" products of the multistep catalytic reactions-at the active site [6-9]. Rubisco activase (RCA) is a member of the AAA+ family of proteins [10] and mediates the activation of Rubisco by facilitating the removal of its inhibitors in an ATP-dependent manner [11-14]. Most plants (including rice) contain two isoforms of RCA generated by alternative splicing: a large isoform of $45-48 \mathrm{kDa}$ and a small isoform of $41-43 \mathrm{kDa}[11,15]$. The large isoform is regulated by the ATP/ADP ratio and redox state in chloroplasts via two cysteine residues 
located in the C-terminal extension, whereas the small isoform is not regulated by redox [16,17]. In rice, the small isoform is more abundant than the large isoform $[18,19]$.

To evaluate the effects of changes in RCA content on photosynthesis, transgenic plants with a reduced or increased RCA content were produced. As the activation state of Rubisco and the $\mathrm{CO}_{2}$ assimilation rate declined only when RCA content was reduced by $>60 \%$ (tobacco, [20-22]; Arabidopsis, [23]; rice, [24-26]), RCA content was considered to be in excess of steady-state photosynthesis. On the other hand, it has been suggested that the activation of Rubisco by RCA would be a limitation for photosynthesis under fluctuating light $[23,26-28]$ and high temperature conditions $[26,29,30]$. Transgenic rice plants with overproduced RCA exhibited a higher activation state of Rubisco and faster photosynthesis induction when the plants were transferred from low to high light intensities [26,31]. However, in such RCA-overproduced rice, Rubisco content was decreased and, consequently, photosynthesis rates were also decreased [31]. Moreover, some studies have shown that Rubisco content was increased in plants with $R C A$ suppression $[20,24,32]$, while other studies reported that Rubisco content did not change in these plants $[21,22,25,33]$. Thus, the effects of RCA levels on Rubisco content in transgenic plants with RCA overproduction or suppression remain uncertain.

In the present study, the effects of RCA levels on Rubisco content were examined in transgenic rice with the overexpression or suppression of $R C A$. We reported previously a difference in the peak timing of gene expression between the Rubisco small subunit $(R B C S)$ gene and $R C A$ in rice plants: the mRNA levels of $R B C S$ reached maxima during leaf expansion, while those of $R C A$ reached maxima after the stage of full expansion [34]. In the RCA-overproduced rice plants generated by Fukayama et al. [31], $R C A$ was overexpressed under the control of the promoter of the chlorophyll a/b-binding protein ( $\mathrm{C} a b)$, which yields peak of gene expression during leaf expansion, similar to that observed for RBCS [35]. Considering these studies, it is possible that the overlap in the expression of the transgenic $R C A$ gene with that of $R B C S$ affects Rubisco biosynthesis. In addition, Fukayama et al. [32] investigated the manner in which the overexpression of $R C A$ affects Rubisco content negatively and reported the possibility that the reduction in Rubisco content occurred at the Rubisco synthesis step. Therefore, in the present study, $R C A$ was overexpressed under the control of the promoters of $R B C S$ or $R C A$ (Pro $R B C S$ or Pro $\left.{ }_{R C A}\right)$. We generated several transgenic rice lines with different levels of RCA content: a $>2$-fold, and 1.5-fold increase. In addition, we obtained transgenic plants with an RCA content that was $<10 \%$ of the wild-type counterpart. Nitrogen $(\mathrm{N})$ is largely invested in chloroplasts as photosynthetic proteins [36]. Rubisco, the most abundant leaf protein, accounts for $10 \%-30 \%$ of total leaf $\mathrm{N}[37,38$ ], and $\mathrm{N}$ allocation to Rubisco increases with increasing leaf $\mathrm{N}$ content in several species including rice $[39,40]$. Thus, we considered the possibility that the effects of RCA levels on Rubisco content were related to leaf $\mathrm{N}$ availability. Therefore, all transgenic lines were grown hydroponically with different $\mathrm{N}$ concentrations. The activation state of Rubisco and the rate of $\mathrm{CO}_{2}$ assimilation were also examined. Finally, we discussed whether it is possible to overproduce RCA without a decrease in Rubisco content and whether the overproduction of RCA leads to an improvement in photosynthesis.

\section{Results}

\subsection{Transgenic Rice Plants with High Increase (HI) and Moderate Increase (MI) in RCA Content}

We transformed the cDNA of the small form of $R C A$ (Os11t0707000-2) in the sense orientation under the control of the RBCS promoter (Pro ${ }_{R B C S}$ ) or of the $R C A$ promoter $\left(\operatorname{Pro}_{R C A}\right)$. We selected two lines with different levels of RCA accumulation for each type of transgenic rice plant: with a $>2$-fold increase in RCA content (high increase lines; $\mathrm{HI}$ ) and with a 50\% increase in RCA content (moderate increase lines; MI). These changes in RCA levels were independent of the promoter used. We also obtained another transgenic line with decreased RCA content, probably caused by a co-suppression effect (severe decrease line; SD). In Western blot analysis, three immunoreactive bands were detected. According to Fukayama et al. [31], these three bands correspond to different RCA isoforms: the large isoform ( $\left(\mathrm{RCA}_{\mathrm{L}}\right.$, top band), the small isoform ( $\mathrm{RCA}_{\mathrm{S}}$, middle band) and processed small isoform 


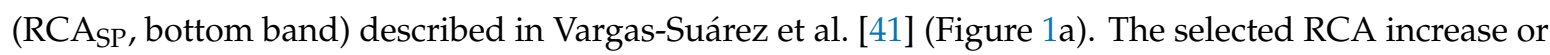
decrease lines, wild-type plants, and null segregants were grown hydroponically with three different $\mathrm{N}$ concentrations $(0.5,2.0$, and $8.0 \mathrm{mM}-\mathrm{N})$. The content of the small form of RCA $\left(\mathrm{RCA}_{\mathrm{S}}\right)$ was increased by $112 \%-212 \%$ and $57 \%-123 \%$ in $\operatorname{Pro}_{R B C S} 13(\mathrm{HI})$ and $\operatorname{Pro}_{R C A} 42(\mathrm{HI})$, and by $63 \%-73 \%$ and $43 \%-93 \%$ in Pro $\operatorname{RBCS} 5$ (MI) and $\operatorname{Pro}_{R C A} 45$ (MI), respectively, relative to wild-type plants. In Pro ${ }_{R B C S} 11$ (SD), the RCA content was less than one-tenth of that detected in wild-type plants (Figure 1b-d). We also determined the mRNA levels of RCA by qRT-PCR in plants grown at $2.0 \mathrm{mM}-\mathrm{N}$. The mRNA levels of $R C A$ were increased by $205 \%, 138 \%, 77 \%$, and $120 \%$ in $\operatorname{Pro}_{R B C S} 13$ (HI), Pro ${ }_{R C A} 42$ (HI), Pro RBCS 5 (MI), and $\operatorname{Pro}_{R C A} 45$ (MI), respectively, and decreased by $80 \%$ in Pro $R B C S 11$ (SD) (Figure 1e). RCA mRNA level was strongly correlated with RCAs protein amount (Figure 1f).

a

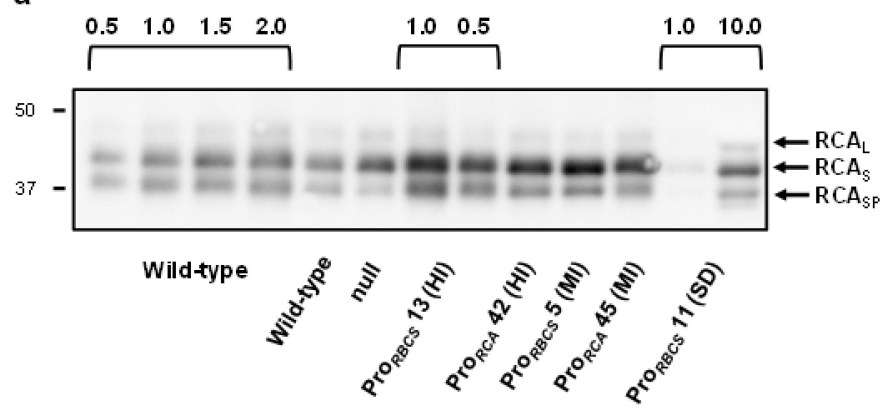

$0.5 \mathrm{mM}-\mathrm{N}$
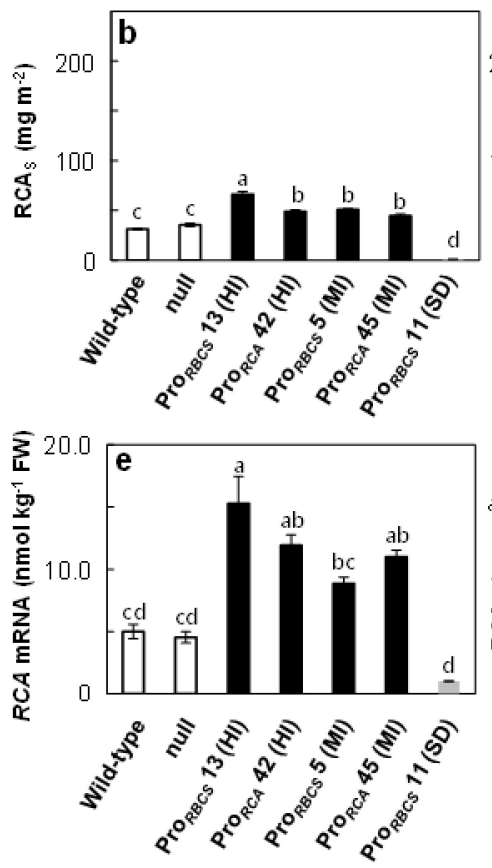

$2.0 \mathrm{mM}-\mathrm{N}$
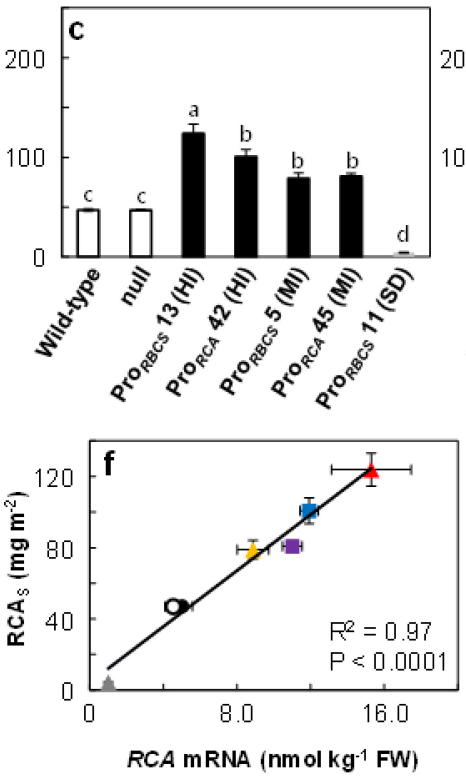

$8.0 \mathrm{mM}-\mathrm{N}$

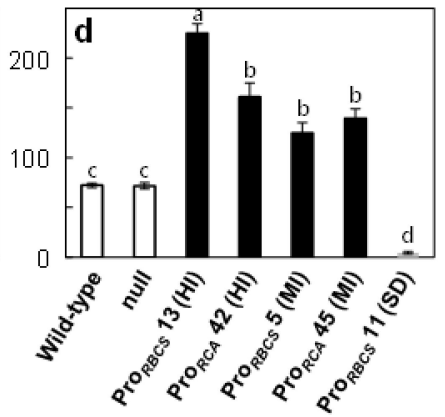

Wild-type

null

$\triangle$ Pro $_{\text {RECS }} 13(\mathrm{HI})$

Pro $_{R C A} 42$ (HI)

- Pro $_{\mathrm{RECS}} 5$ (MI)

- Pro $_{\mathrm{BCA}} 45$ (M)

$\triangle$ Pro $_{R E C S} 11$ (SD)

Figure 1. Detection of the Rubisco activase (RCA) protein and the RCA mRNA levels in RCA transgenic rice plants. (a) Detection of RCA in uppermost, fully expanded leaves at $2.0 \mathrm{mM}-\mathrm{N}$ concentration by Western blot analysis. Aliquots of SDS-treated samples at a volume corresponding to $0.1 \mu \mathrm{g}$ of total leaf-N were subjected to SDS-PAGE. RCA was detected using specific antibodies after SDS-PAGE. The arrows indicate each isoform of RCA (large isoform of RCA $\left(R C A_{L}\right)$, small isoform of RCA (RCAs), and processed small isoform of RCA (RCASP), described in [31]). (b-d) RCAs content in a leaf area in uppermost, fully expanded leaves at 0.5, 2.0 and $8.0 \mathrm{mM}-\mathrm{N}$ concentrations. (e) $R C A \mathrm{mRNA}$ levels in expanding leaves of plants grown at $2.0 \mathrm{mM}-\mathrm{N}$, on a tissue weight basis. The white, black, and grey bars indicate wild-type and null plants, RCA-overproduced plants, and plants with RCA suppression, 
respectively. (f) Relationship between RCA protein content and RCA mRNA level in plants grown at $2.0 \mathrm{mM}-\mathrm{N}$. The linear regression line was calculated from datapoints using Pearson's coefficient of correlation. The black circle, white circle, red triangle, blue square, yellow triangle, purple square, and grey triangle indicate wild-type, null, $\operatorname{Pro}_{R B C S} 13(\mathrm{HI}), \operatorname{Pro}_{R C A} 42(\mathrm{HI}), \operatorname{Pro}_{R B C S} 5(\mathrm{MI}), \operatorname{Pro}_{R C A} 45$ (MI), and Pro ${ }_{R B C S} 11$ (SD) plants, respectively. Data are means \pm SE $(n=3-5)$. Statistical analysis was carried out by ANOVA with a post hoc Tukey-Kramer's HSD test. Different letters indicate significant differences among genotypes $(p<0.05)$.

\subsection{Effects of Changes in RCA Content on Rubisco Levels in Plants Treated with Three Different $N$ Concentrations}

The total leaf $\mathrm{N}$ content did not differ among the genotypes for each $\mathrm{N}$ treatment (Figure 2a-c). In both RCA-HI lines, Rubisco content tended to decrease compared to the wild-type plants at 0.5 and $2.0 \mathrm{mM}-\mathrm{N}$, but was not different at $8.0 \mathrm{mM}-\mathrm{N}$. Rubisco contents of the two RCA-MI lines did not differ within the same $\mathrm{N}$ treatment. In Pro ${ }_{R B C S} 11$ (SD), Rubisco content was increased in the $0.5 \mathrm{mM}-\mathrm{N}$ treatment, but was not different at 2.0 and $8.0 \mathrm{mM}-\mathrm{N}$ (Figure $2 \mathrm{~d}-\mathrm{f}$ ). These results suggest that, although the changes in RCA content tended to affect Rubisco levels negatively, these effects depended on the amount of $\mathrm{N}$ supply. Conversely, there were no differences in transketolase content among genotypes within the same $\mathrm{N}$ treatment (Figure 2g-i).

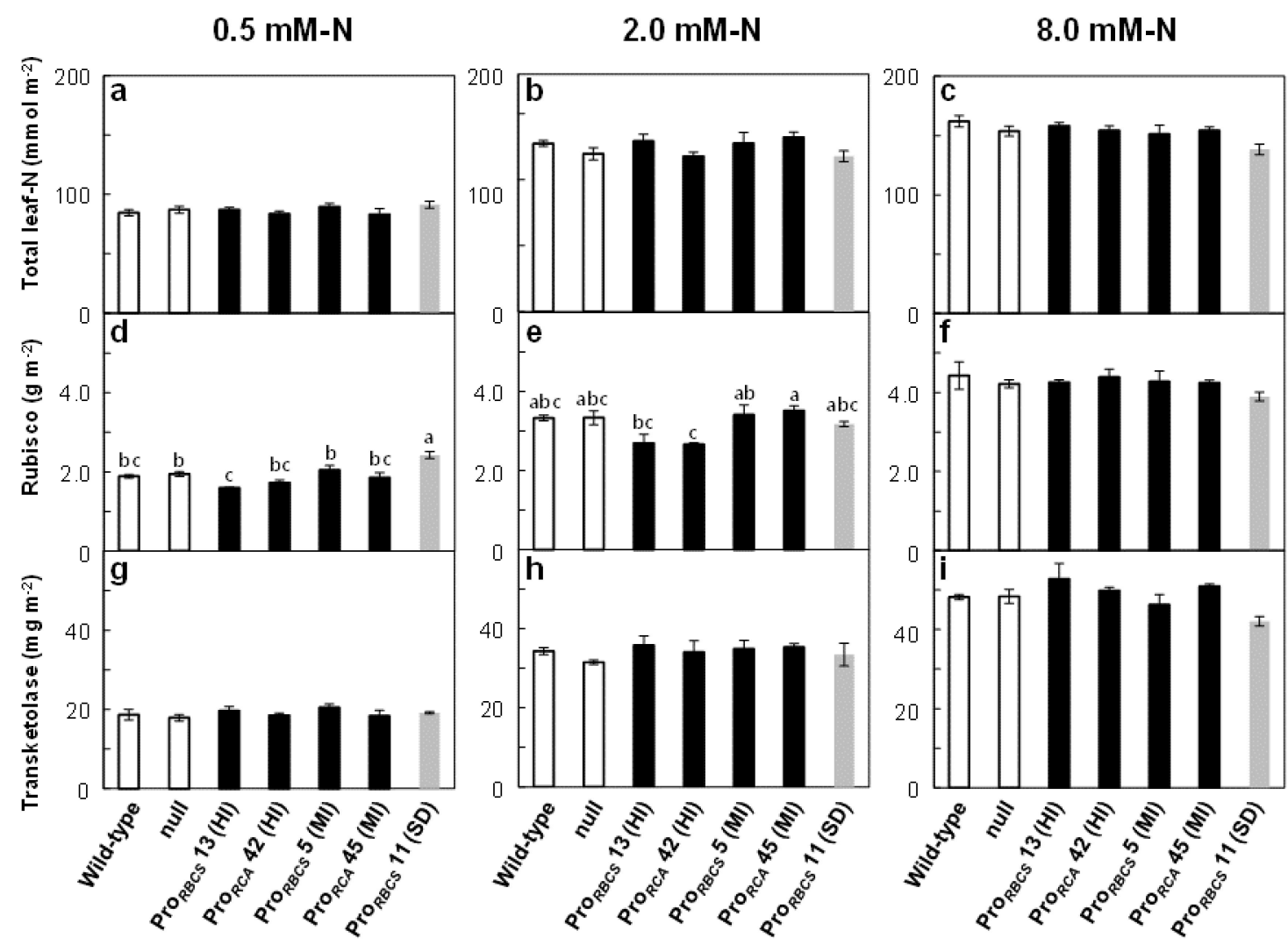

Figure 2. Total leaf-N, Rubisco, and transketolase contents in RCA transgenic plants. (a-c) Total leaf-N, (d-f) Rubisco, and (e-i) transketolase contents in a leaf area in uppermost, fully expanded leaves at $0.5,2.0$ and $8.0 \mathrm{mM}-\mathrm{N}$ concentrations. The white, black, and grey bars indicate wild-type and null plants, RCA-overproduced plants, and plants with RCA suppression, respectively. Data are means \pm SE $(n=3-5)$. Statistical analysis was carried out by ANOVA with a post hoc Tukey-Kramer's HSD test. Different letters indicate significant differences among genotypes $(p<0.05)$.

Figure 3 shows the ratios of the $\mathrm{N}$ allocated to RCA, Rubisco, and transketolase to total leaf-N content in the three $\mathrm{N}$ concentrations. RCA $\mathrm{S}-\mathrm{N}$ was increased by $105 \%-219 \%, 58 \%-133 \%, 53 \%-85 \%$, and 45\%-103\% in Pro $_{R B C S} 13$ (HI), Pro $R C A 42$ (HI), Pro ${ }_{R B C S} 5$ (MI), and Pro $R C A 45$ (MI) compared to 
the wild-type plants, and was greatly decreased in $\operatorname{Pro}_{R B C S} 11$ (SD) (to $<10 \%$ ) (Figure 3a-c). In Pro RBCS 13 (HI) compared to wild-type plants, Rubisco-N was significantly decreased, by $18 \%$ in $0.5 \mathrm{mM}-\mathrm{N}$ and by $23 \%$ in $2.0 \mathrm{mM}-\mathrm{N}$ growth conditions. In $\mathrm{Pro}_{R C A} 42$ (HI) compared to wild-type, Rubisco-N was also decreased by $16 \%$ at $2.0 \mathrm{mM}-\mathrm{N}$, and tended to decrease at $0.5 \mathrm{mM}-\mathrm{N}$. On the other hand, Rubisco-N in Pro $_{R B C S} 13$ (HI) and Pro $R C A$ A2 (HI) was unchanged at $8.0 \mathrm{mM}-\mathrm{N}$. Rubisco-N was increased by $19 \%$ in Pro ${ }_{R B C S} 11$ (SD) grown at $0.5 \mathrm{mM}-\mathrm{N}$ and was unchanged at 2.0 and $8.0 \mathrm{mM}-\mathrm{N}$. In contrast, Rubisco-N was unchanged in the two RCA-MI lines at any N concentration (Figure $3 \mathrm{~d}-\mathrm{f}$ ). On the other hand, there was no difference in transketolase-N, regardless of genotype (Figure $3 \mathrm{~g}-\mathrm{i}$ ). As the increase or decrease in $\mathrm{N}$ allocation to RCA by transgenesis corresponded to only $<1 \%$ of the total leaf-N content, the changes in Rubisco content observed in transgenic lines were not explained by the changes in the amount of RCA.

$0.5 \mathrm{mM}-\mathrm{N}$

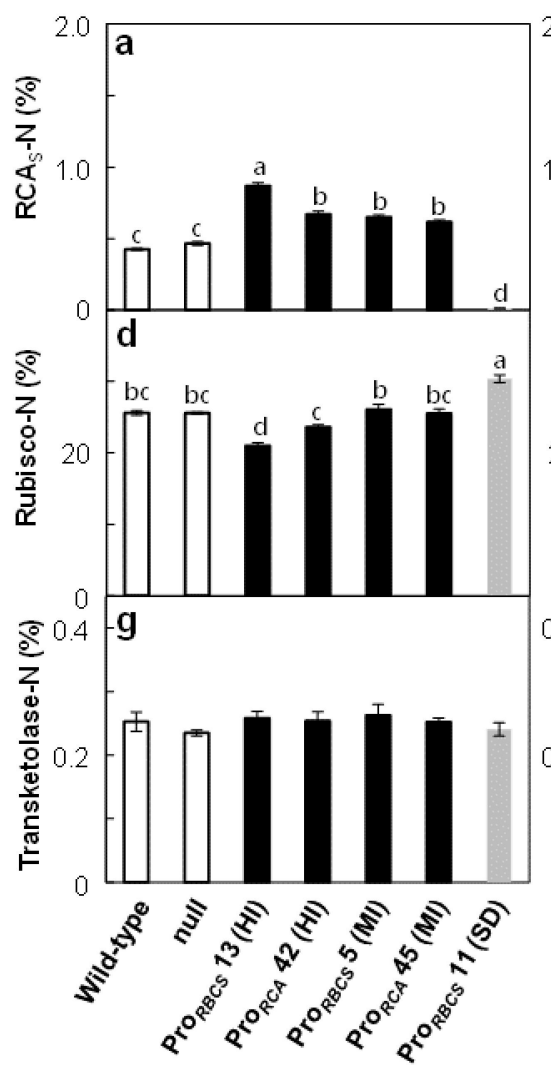

$2.0 \mathrm{mM}-\mathrm{N}$

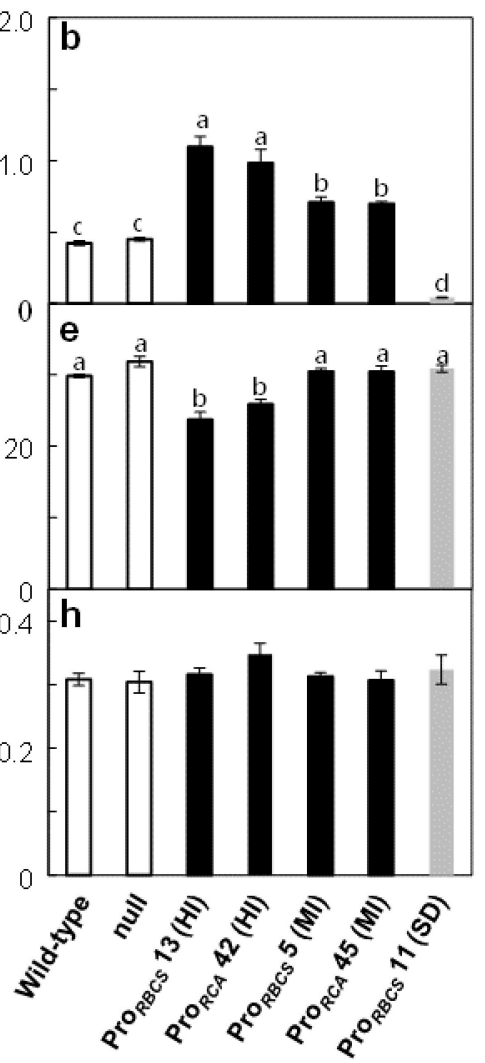

$8.0 \mathrm{mM}-\mathrm{N}$

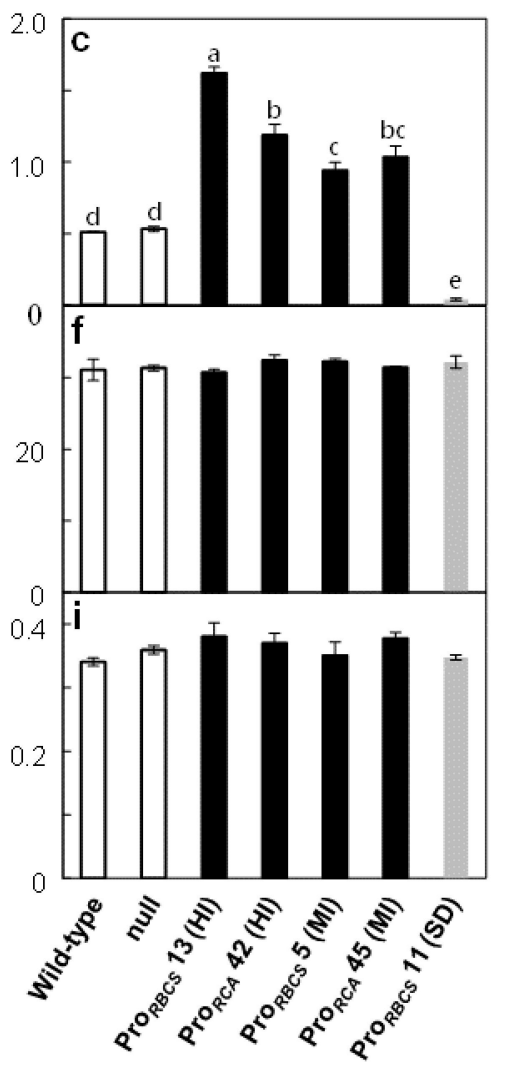

Figure 3. $\mathrm{N}$ allocation to $\mathrm{RCA}_{\mathrm{S}}$, Rubisco, and transketolase in RCA transgenic plants. (a-c) Rubisco-N, (d-f) RCA $-\mathrm{N}$, and (g-i) transketolase-N in uppermost, fully expanded leaves at 0.5, 2.0 and $8.0 \mathrm{mM}-\mathrm{N}$ concentrations. The ratio of $\mathrm{N}$ contained in each protein to total leaf- $\mathrm{N}$ was estimated using a conversion factor of 0.16 for $\mathrm{N}$ to protein. The white, black, and grey bars indicate wild-type and null plants, RCA-overproduced plants, and plants with $R C A$ suppression, respectively. Data are means \pm SE $(n=3-5)$. Statistical analysis was carried out by ANOVA with a post hoc Tukey-Kramer's HSD test. Different letters indicate significant differences among genotypes $(p<0.05)$.

The relationships between Rubisco-N, RCA $-\mathrm{N}$, and total leaf-N contents were examined (Figure 4).

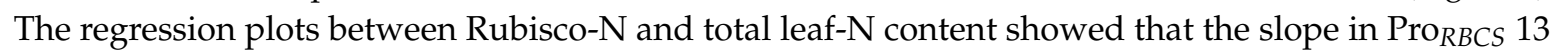
(HI) was significantly steeper, and the slope in $\operatorname{Pro}_{R C A} 42$ (HI) was slightly steeper, than that observed in wild-type plants. In the two RCA-MI lines, the regression slopes were similar to those detected in wild-type plants. Conversely, the slope in Pro $_{R B C S} 11$ (SD) was significantly slower vs. the wild-type one. The differences in Rubisco-N between RCA transgenic and wild-type plants decreased with 
increasing total leaf-N content: at the maximum total leaf-N content, Rubisco-N converged to $30 \%$ of total leaf-N, regardless of genotype (Figure $4 \mathrm{a}-\mathrm{c}$ ). It was reported that a value of $30 \%$ in Rubisco-N is close to maximum levels in rice plants $[4,38,42-44]$. These results clearly showed that the effects of the changes in RCA content on Rubisco levels depended on total leaf-N content. The regression plots between RCAS-N and total leaf-N content showed that the slopes in the RCA-HI and Pro PCA $_{S}$ 45 (MI) lines were steeper, and the slope in Pro ${ }_{R B C S} 5$ (MI) was slightly steeper, than that observed for the wild-type plants (Figure $4 \mathrm{~d}-\mathrm{f}$ ). Thus, the increase in $\mathrm{N}$ allocation to RCA by transgenesis was augmented by increasing the total leaf- $\mathrm{N}$ content.

WT vs RCA HI
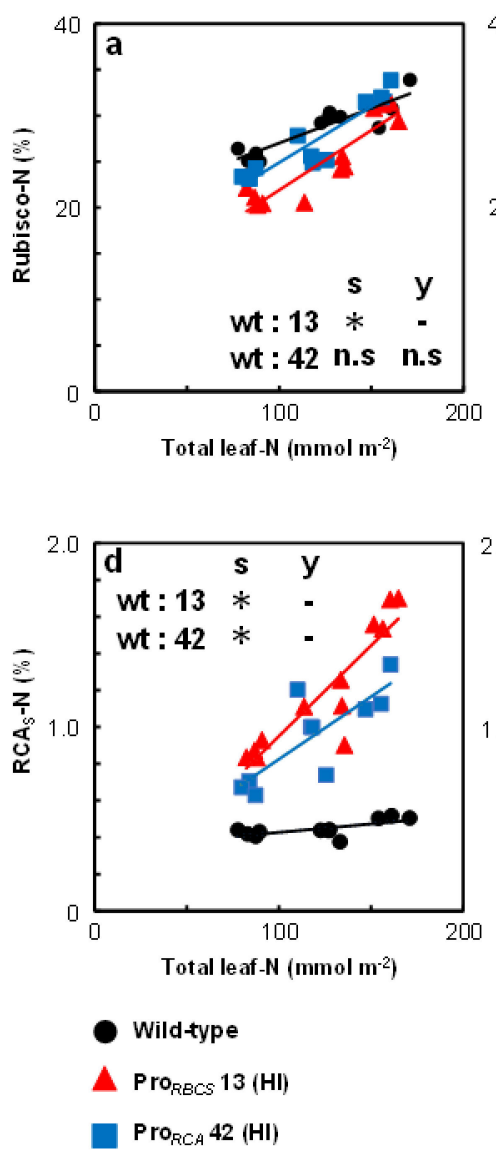

WT vs RCA MI
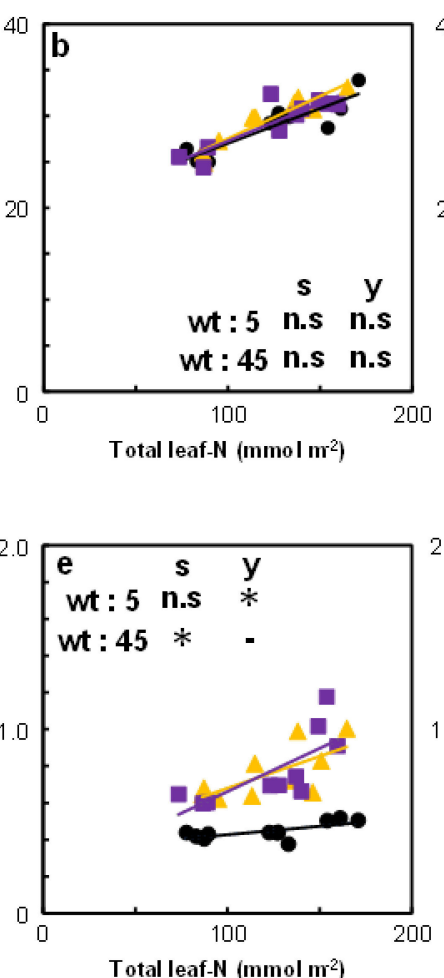

$\triangle \operatorname{Pro}_{\text {RECS }} 5$ (MI)

Pro $_{R C A} 45$ (M)
WT vs RCA SD
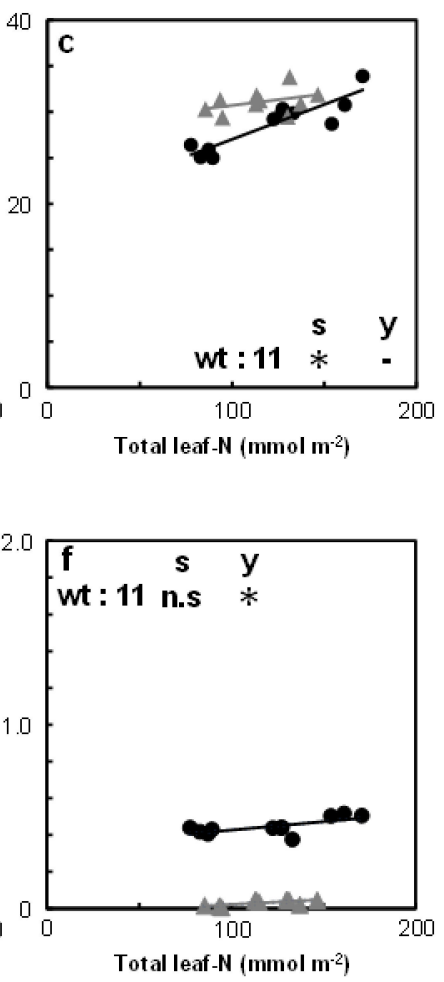

$\triangle \operatorname{Pro}_{\mathrm{FECS}} 11(\mathrm{SD})$

Figure 4. Relationships between Rubisco-N and $\mathrm{RCA}_{\mathrm{S}}-\mathrm{N}$ and total leaf-N contents in RCA transgenic plants. The data were taken from Figures 2 and 3. (a-c) Relationships between Rubisco-N and total leaf- $\mathrm{N}$ and (d-f) RCAS-N and total leaf- $\mathrm{N}$ in uppermost, fully expanded leaves. The black circle, red triangle, blue square, yellow triangle, purple square, and grey triangle indicate wild-type, $\operatorname{Pro}_{R B C S}$ 13 (HI), Pro ${ }_{R C A} 42$ (HI), Pro $R B C S 5$ (MI), Pro $R C A 45$ (MI), and Pro ${ }_{R B C S} 11$ (SD) plants, respectively. The asterisks denote a statistically significant difference, as assessed by analysis of covariance (ANCOVA) $(p<0.05)$ performed on the slope (s) and y-intercept (y) of the linear regressions between wild-type and RCA transgenic plants, respectively. The details of the statistical treatments are presented in Tables S1 and S2.

\subsection{Activation State of Rubisco and the Rate of $\mathrm{CO}_{2}$ Assimilation in Transgenic Rice Plants}

To examine the effects of overproduction of RCA on photosynthesis, the activation state of Rubisco and the rate of $\mathrm{CO}_{2}$ assimilation under conditions of ambient $\left[\mathrm{CO}_{2}\right]$ partial pressures $(\mathrm{Ca}=40 \mathrm{~Pa})$ and high and low irradiances (PPFD of 1500 and $100 \mu \mathrm{mol}$ quanta $\mathrm{m}^{-2} \mathrm{~s}^{-1}$ ) were measured in plants grown at $2.0 \mathrm{mM}-\mathrm{N}$ (Figure 5). Under high irradiance conditions, the activation state of Rubisco in Pro $_{R B C S} 13$ (HI) was significantly higher, and the activation state of Rubisco in other RCA overproduced 
plants tended to be higher than that in wild-type plants (Figure 5a). However, the rate of $\mathrm{CO}_{2}$ assimilation did not increase in RCA-overproduced plants compared to wild-type plants (Figure $5 b$ ). Conversely, the activation state of Rubisco and the rate of $\mathrm{CO}_{2}$ assimilation in $\mathrm{Pro}_{R B C S} 11$ (SD) were significantly lower than in wild-type plants. Similar results were reported in previous studies with $R C A$-suppressed rice plants $[24,25]$. Under low irradiance conditions, although the activation state of Rubisco in RCA-overproduced plants also tended to be higher than in wild-type plants, there was no increase in the rate of $\mathrm{CO}_{2}$ assimilation (Figure $5 \mathrm{c}, \mathrm{d}$ ).
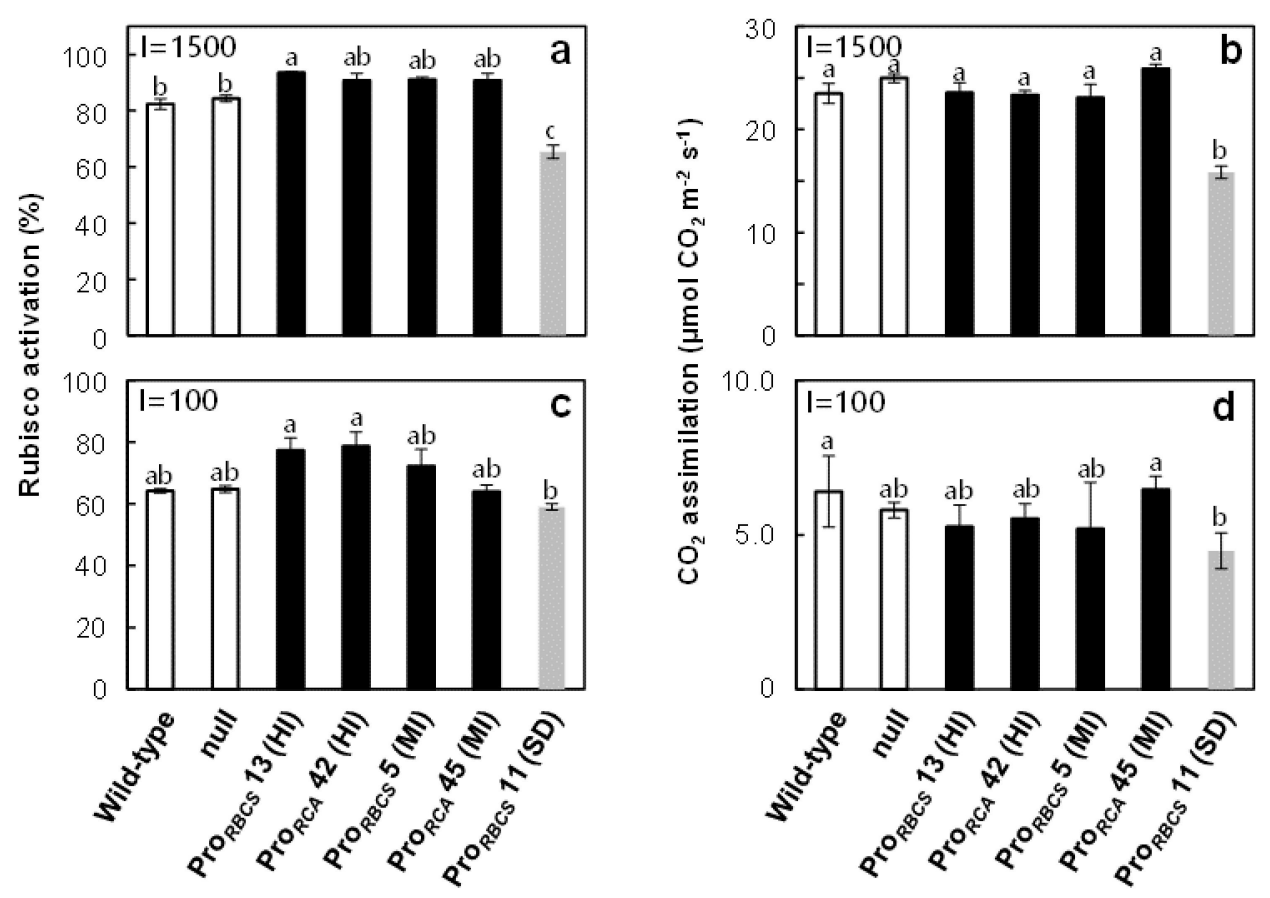

Figure 5. $(\mathbf{a}, \mathbf{c})$ Rubisco activation and $(\mathbf{b}, \mathbf{d})$ the rates of $\mathrm{CO}_{2}$ assimilation at an ambient $\mathrm{CO}_{2}$ partial pressure $(\mathrm{Ca}=40 \mathrm{~Pa})$ and high and low irradiances (PPFD of 1500 and $100 \mu \mathrm{mol}$ quanta $\mathrm{m}^{-2} \mathrm{~s}^{-1}$ ). Measurement were done on uppermost, fully expanded leaves in plants grown at $2.0 \mathrm{mM}-\mathrm{N}$. The white, black, and grey bars indicate wild-type and null plants, RCA-overproduced plants, and plants with $R C A$ suppression, respectively. Data are means \pm SE $(n=3-5)$. Statistical analysis was carried out by ANOVA with a post hoc Tukey-Kramer's HSD test. Different letters indicate significant differences among genotypes $(p<0.05)$.

\section{Discussion}

Many studies have shown that RCA and Rubisco are attractive targets for improving photosynthesis (for a review, see [4]). However, Fukayama et al. [31,32] reported that the overproduction of RCA negatively affected Rubisco content. To assess whether it is possible to overproduce RCA without affecting Rubisco content, we generated and selected several transgenic rice plants exhibiting varying RCA levels under the control of two different promoters (Figure 1) and examined the effects of changes in RCA levels on Rubisco content in plants grown with different $\mathrm{N}$ concentrations. Our results showed that although changes in RCA levels tended to affect Rubisco content negatively, these effects depended on $\mathrm{N}$ supply and were diminished with increasing total leaf-N content (Figures 2-4). In addition, Rubisco levels were unchanged in transgenic rice plants, with a 50\% increase in RCA content regardless of N concentration (Figures 2-4). These results showed that overproduction of RCA without a decrease in Rubisco content was feasible via a moderate increase in RCA levels. The effects of changes in RCA content on Rubisco levels are discordant between previous studies of rice plants with RCA suppression: Jin et al. [24] showed that Rubisco content was increased, whereas Masumoto et al. [25] did not find such an increase in Rubisco content in those plants. Our results (Figures 2-4) indicate the possibility 
that the differences observed between the studies of Jin et al. [24] and Masumoto et al. [25] were caused by differences in $\mathrm{N}$ availability (summarized in Table $\mathrm{S} 3$ ). We observed a significant increase in Rubisco content exclusively in the low-N-grown RCA-suppressed plants (Figure 2).

Previously, we found a negative correlation between the amounts of Rubisco and RCA in transgenic rice plants with increased or decreased Rubisco content. However, such a negative correlation was also observed for enzymes of the Calvin-Benson cycle. Therefore, these phenomena were non-specific effects that were accounted for by changes in $\mathrm{N}$ allocation caused by changes in Rubisco content [45]. In contrast, in the present study of RCA-transgenic plants, the amounts of transketolase and transketolase-N were not affected (Figures 2 and 3). Similarly, Fukayama et al. [32] reported no changes in several Calvin-Benson cycle enzymes in RCA-transgenic rice plants. These results suggest that the changes in RCA content affected Rubisco levels selectively. In addition, as changes in $\mathrm{N}$ allocation to RCA $A_{S}$ in RCA-transgenic plants corresponded to less than $1 \%$ of the total leaf-N content (Figure 3), the changes in Rubisco content observed in transgenic plants were not explained by the changes in the amount of RCA. Therefore, although we observed a negative correlation between Rubisco and RCA content when the amounts of RCA or Rubisco were genetically manipulated, the effects of changes in RCA content on Rubisco levels in RCA-transgenic plants were different from those detected in Rubisco-transgenic plants.

Our results showed that although the levels of the Rubisco protein were decreased in RCA-HI plants, the mRNA levels of $R B C S$ and of the Rubisco large subunit $(R B C L)$ gene remained unchanged (Figure S1). Similar results were obtained for the $R C A$-overexpressing rice plants reported by Fukayama et al. [31,32]. These results suggest that Rubisco content is regulated post-transcriptionally. It has been suggested that the unassembled RBCL protein interacts with the RBCL mRNA, leading to a decline in its polysome loading and the suppression of its translation in tobacco plants $[46,47]$. This assembly-dependent translational regulation mechanism is termed control by epistasy of synthesis (CES) [48]. In our previous studies of rice plants [49,50], the amount of RBCL loading on polysomes was decreased in senescent leaves, although regulation at the transcription level principally controls RBCL protein synthesis. This suggests that CES regulation is also effective in controlling RBCL synthesis in a senescent rice leaf. Although Fukayama et al. [32] reported the possibility that the translation activities of $R B C S$ and $R B C L$ did not greatly change in $R C A$-overexpressing rice plants, it is unclear whether the small decline in Rubisco content observed in RCA-overproduced rice plants was caused by CES regulation of $R B C L$.

We reported previously that the mRNA levels of $R B C S$ reached maxima during leaf expansion, followed by a rapid decrease, while those of $R C A$ reached maxima after the stage of full expansion to senescence [34]. In addition, based on the argument that RCA affects Rubisco synthesis negatively, described in Fukayama et al. [32], we considered the possibility that the overlap in the expression of the RCA transgene with that of the RBCS gene affects Rubisco biosynthesis. Therefore, we used Pro $_{R B C S}$ and Pro ${ }_{R C A}$ for the overproduction of RCA. However, Rubisco content decreased in RCA-HI plants and did not decrease in RCA-MI plants, regardless of the promoter that was used (Figures 2 and 3). Thus, Rubisco content was not affected by the difference in two promoters used for RCA overproduction, but by the magnitude of overproduction of RCA.

The activation state of Rubisco tended to increase in RCA-overproduced plants (Figure 5), which is consistent with the previous study [31]. It was considered that the enhancement of Rubisco activation compensated for the decrease in Rubisco content in RCA-HI plants. On the other hand, in RCA-MI plants, the effects of enhancement of Rubisco activation on the rate of $\mathrm{CO}_{2}$ assimilation were not observed (Figure 5). This is probably because under ambient $\left[\mathrm{CO}_{2}\right]$ conditions, the rate of $\mathrm{CO}_{2}$ assimilation was mainly limited by Rubisco capacity, but also partly limited by RuBP regeneration capacity. Our previous studies showed that the overproduction of Rubisco did not necessarily enhance photosynthesis because of decreased Rubisco activation, probably due to a decrease in RCA content $[45,51-53]$. Thus, we considered that overproduction of both Rubisco and RCA is essential to improve photosynthesis, especially under low $\left[\mathrm{CO}_{2}\right]$ conditions. On calculation, an increase in RCA content of $50 \%-60 \%$ in RCA-MI plants is considered to be sufficient to compensate for the decrease in 
RCA levels caused by Rubisco overproduction. In a future study, we will attempt to generate transgenic rice plants with co-overproduction of Rubisco and RCA, to enhance the photosynthetic capacity.

\section{Materials and Methods}

\subsection{Generation of Transgenic Plants}

The binary vector pBIRS [51] was digested with HindIII and SacI. A DNA fragment of the region corresponding to -3000 to +36 from the start codon of the small form of $R C A$ [Os11t0707000-2; RAP-DB [54]] was amplified as its promoter region $\left(\right.$ Pro $_{R C A}$ ) by genomic PCR using PrimeSTAR HS (TAKARA, Shiga, Japan) and the following primer pair: 5'-TGATTACGCCAAGCTTAATGCTTGAAATATAATGCTGCG-3' and 5'-CGGAGCTCCAACGGTGGAG-3'. A DNA fragment from position +22 from the $R C A$ start codon to its end was amplified from the cDNA template of rice (Oryza sativa L. cv Notohikari) by PrimeSTAR HS with the following primer pair: 5'-ACCGTTGGAGCTCCGGCGT-3' and 5'-GATCGGGGAAATTCG AGCTCAATGAAATATACTCATGTATAGTAT-3'. A DNA fragment containing the open reading frame (ORF) and the $5^{\prime}$ untranslated region (5'-UTR) of $R C A$ was amplified. A cDNA template was amplified by reverse-transcription PCR (RT-PCR) using SuperScript $囚 I I I$ Reverse Transcriptase (Thermo Fisher Scientific, Yokohama, Japan). The digested pBIRS and the amplified DNA fragment were fused using an In-Fusion HD Cloning Kit (Mountain View, Clontech, CA, USA) according to the manufacturer's instructions, to generate a vector for the overexpression of $R C A$ under the control of its own promoter ( $\left(\operatorname{Pro}_{R C A}\right)$. The RBCS promoter ( Pro $_{R B C S}$ ) (2.8 kb fragment of the rice RBCS promoter, as described by Kyozuka et al. [55]) was amplified using PrimeSTAR HS and the following primer pair: 5'-TGATTACGCCAAGCTTGCATGCCT-3' and 5'-CGGCCGCTGCTGCTCAAGCTTATCGATACCGTCGAC-3'. A DNA fragment corresponding to positions -62 from the $R C A$ start codon to its end was amplified from the cDNA template by primeSTAR HS using the following primer pair: 5'-GAGCAGCAGCGGCCGGC- $3^{\prime}$ and 5'-GATCGGGGAAATTCGAGCTCAATGAAATATACTCATGTATAGTAT-3'. The digested pBIRS and the amplified DNA fragment were fused using an In-Fusion HD Cloning Kit to generate a vector for the overexpression of $R C A$ under the control of the RBCS promoter ( $\left.\operatorname{Pro}_{R B C S}\right)$.

Rice (Oryza sativa L. cv Notohikari) was transformed using the agrobacterium method [56]. The $\mathrm{T}_{0}$ progenies of transgenic plants were grown hydroponically in an isolated greenhouse [2]. Transgenic plants with an increase in RCA content were screened and self-fertilized to collect $\mathrm{T}_{1}$ seeds. Selections of homozygotes were performed using the comparative cycle threshold method, as described by Suzuki et al. [57]. The primer pairs used in this experiment were as follows: 5'-CAATTTCACACAGGAAACAGCTATG-3' and 5'-TTTGCTGCAGCATGCA-3' for Pro ${ }_{R B C S}$ RCA-overexpressing (ox) plants and 5'-GGATAACAATTTCACACAGGAAACA-3' and 5'-CGCAGCATT ATATTTCAAGCATTAA-3' for $\operatorname{Pro}_{R C A} R C A$ ox plants. The probes used were as follows: reporter, FAM; quencher, NFQ-MGB; 5'-CCATGATTACGCCAAGC-3' for Pro ${ }_{R B C S} R C A$ ox plants and 5'-CTATGACCATGATTACGC-3' for $\operatorname{Pro}_{R C A} R C A$ ox plants. The selected $\mathrm{T}_{1}$ progenies were allowed to self-fertilize, to collect $\mathrm{T}_{2}$ seeds. We also screened transgenic plants with a decrease in RCA content caused by co-suppression and collected $\mathrm{T}_{2}$ seeds, as described above. Null segregants were also selected and self-fertilized to collect $\mathrm{T}_{2}$ seeds. Two lines each of the $\mathrm{T}_{2}$ progenies of $\operatorname{Pro}_{\text {RBCS }} R C A$ ox plants and $\operatorname{Pro}_{R C A} R C A$ ox plants and one line with $R C A$ suppression were used in this study. Both null segregant lines derived from Pro $_{R B C S}$ transgenic plants and from Pro $_{R C A}$ transgenic plants were used. The data from all null segregant lines were aggregated into a single "null", used for analysis. To confirm that both null segregant lines showed trends similar to wild-type plants, segregants lines derived from Pro PBCS $_{\text {plants }}$ or Pro ${ }_{R C A}$ plants were grouped and analyzed separately in Figure S2. Relationships of total leaf-N with RCA content and total leaf-N with Rubisco content did not differ between wild-type and the two null segregant lines. 


\subsection{Plant Culture and Sampling}

Plants were grown hydroponically in an environmentally controlled growth chamber, as described by Suganami et al. [45], with slight modifications. The growth chamber was operated with a PPFD of $800 \mu \mathrm{mol}$ quanta $\mathrm{m}^{-2} \mathrm{~s}^{-1}$, a $15 \mathrm{~h}$ photoperiod and a day/night temperature of $26 / 20^{\circ} \mathrm{C}$. From the $63 \mathrm{rd}$ to 77th day after sowing, the uppermost, fully expanded leaves were collected after measurement of the rate of $\mathrm{CO}_{2}$ assimilation and stored at $-80{ }^{\circ} \mathrm{C}$ until biochemical assays. For the determination of mRNA levels, leaves that had emerged from their sheaths by $60 \%$ were collected. Samplings were done between 11:00 and 13:00, from the 4th to 7th day after renewal of the nutrient solution.

\subsection{Measurement of Gas Exchange}

Measurements of the $\mathrm{CO}_{2}$ assimilation rate were performed using a portable gas exchange system (LI-6400XT, Li-Cor, Lincoln, NE, USA). Conditions in the chamber were as follows: leaf temperature of $25^{\circ} \mathrm{C}$, Ca of $40 \mathrm{~Pa}$, leaf-to-air vapor pressure difference of $1.0-1.2 \mathrm{kPa}$, relative humidity of $60 \%-70 \%$, PPFD of 1500 or $100 \mu \mathrm{mol}$ quanta $\mathrm{m}^{-2} \mathrm{~s}^{-1}$. The steady state of gas exchange rate was obtained. To compute $\mathrm{CO}_{2}$ assimilation rate, gas exchange parameters were calculated according to equations of von Caemmerer and Farquhar [58].

\subsection{Biochemical Assay}

The amounts of total leaf-N, Rubisco, small form of RCA ( RCA $\left._{S}\right)$ and transketolase were determined on the same leaf. The frozen leaves were homogenized in Na-phosphate buffer ( $\mathrm{pH}$ 7.0) containing $2 \mathrm{mM}$ iodoacetic acid, $120 \mathrm{mM}$ 2-mercaptoethanol, and 5\% (v/v) glycerol. The total $\mathrm{N}$ content in leaves was determined using Nessler's reagent after Kjeldahl digestion [42]. Rubisco content was determined spectrophotometrically after formamide extraction of Coomassie Brilliant Blue (CBB) R-250-stained bands corresponding to the large and small subunits of Rubisco separated by SDS-PAGE. A calibration curve was prepared with Rubisco purified from rice [59]. RCA $A_{S}$ and transketolase contents were determined by image analysis after SDS-PAGE followed by CBB G-250 staining, as described by Suganami et al. [45], with slight modification. Exceptionally, because RCA content in Pro $_{R B C S}$ SD plants could not be quantified via CBB staining, Western blot analyses were used to quantify the protein in these plants, as described by Suzuki et al. [57]. Antibodies against RCA were purchased from Agrisera (Vännäs, Sweden). For the calculation of $\mathrm{N}$ allocation to Rubisco, $\mathrm{RCA}_{S}$ and transketolase, a nitrogen to protein conversion factor of 0.16 was used.

Rubisco activity was measured spectrophotometrically by coupling 3-phosphoglyceric acid formation with $\mathrm{NADH}$ oxidation at $25^{\circ} \mathrm{C}$, according to [60], with slight modification. The samples used for the Rubisco activation assay were collected from a leaf that was equilibrated at steady-state conditions. After exposure to at least $30 \mathrm{~min}$ of illumination (PPFD of 1500 or $100 \mu \mathrm{mol}$ quanta $\mathrm{m}^{-2} \mathrm{~s}^{-1}$ ) in the chamber of the portable gas exchange system (LI-6400XT, Li-Cor) and after gas exchange had reached the steady-state rate (leaf temperature of $25^{\circ} \mathrm{C}$, Ca of $40 \mathrm{~Pa}$ ), the leaf was quickly frozen in liquid $\mathrm{N}_{2}$. The frozen leaf was quickly (within $30 \mathrm{~s}$ ) homogenized in $50 \mathrm{mM}$ HEPES/NaOH ( $\mathrm{pH}$ 8.0) containing $20 \mathrm{mM} \mathrm{MgCl}_{2}, 10 \mathrm{mM}$ dithiothreitol, and the protease inhibitor cocktail Complete Mini (Roche, Manheim, Germany) using an ice-chilled mortar and pestle. After centrifugation at $4{ }^{\circ} \mathrm{C}$ for $10 \mathrm{~s}$, a portion of the supernatant was injected into a reaction mixture of $100 \mathrm{mM} \mathrm{HEPES} / \mathrm{NaOH}$ (pH 8.0) containing $20 \mathrm{mM} \mathrm{MgCl}_{2}, 5 \mathrm{mM}$ dithiothreitol, $5 \mathrm{mM}$ ATP, $5 \mathrm{mM}$ phosphocreatine, $0.2 \mathrm{mM} \mathrm{NADH}$, $100 \mathrm{mM} \mathrm{NaHCO}_{3}, 0.5 \mathrm{mM}$ ribulose 1,5-bisphosphate (RuBP), $25 \mathrm{U} \mathrm{mL}^{-1}$ of glyceraldehyde-3-phosphate dehydrogenase, $25 \mathrm{U} \mathrm{mL}^{-1}$ of 3-phosphoglycerate kinase, and $25 \mathrm{U} \mathrm{mL}^{-1}$ of creatine phosphokinase. Total activity was measured in the supernatant after incubation with $100 \mathrm{mM} \mathrm{NaHCO}_{3}$ and $20 \mathrm{mM}$ $\mathrm{MgCl}_{2}$. The activation state was taken as the ratio of the initial activity to the total activity. 


\subsection{RNA Analysis}

Analyses of mRNA levels were done on expanding leaves of plants grown at $2.0 \mathrm{mM}-\mathrm{N}$. Total RNA was extracted according to the method of Suzuki et al. [61], with slight modification [53]. The mRNA levels were determined by quantitative reverse transcription PCR (qRT-PCR) according to Ogawa et al. [62]. The used primer pairs for $R C A$ can be found in Yamaoka et al. [34] and those for $R B C S$ and $R B C L$ can be found in Suzuki et al. [53].

\subsection{Statistical Treatments}

Data are means \pm SE. Data shown in Figures 1-3, Figure 5, and Figure S1 were statistically analyzed with ANOVA followed by the post hoc Tukey-Kramer's HSD test $(p<0.05)$. First, one-way ANOVA was used to test for statistically significant differences between means of each trait among the seven genotypes. If a significant difference was found, post hoc Tukey-Kramer's HSD test was carried out for multiple pairwise comparisons. The relationships between datasets in Figure 1f, Figure 4, and Figure S2 were evaluated using Pearson's correlation coefficient. Data shown in Figure 4 were statistically analyzed by analysis of covariance (ANCOVA). First, the slopes of regression line were tested; if no significant difference was found, intercepts were then tested. All analyses were carried out using JMP11 (SAS Institute Japan, Tokyo, Japan).

Supplementary Materials: Supplementary Materials can be found at http://www.mdpi.com/1422-0067/21/5/1626/ s1.

Author Contributions: A.M. and Y.S. conceived and designed the experiments. E.K., S.N., M.S., S.K. and Y.S. produced transgenic plants. M.S. mainly performed the experiments. E.K., S.N. and S.K. also performed some parts of the experiments. M.S., E.K., S.N., S.K., Y.S. and A.M. analyzed the data. M.S. wrote the original manuscripts and M.S, Y.S and A.M wrote, reviewed and edited the manuscripts. All authors have read and agreed to the published version of the manuscript.

Funding: This work was supported by Grants-in-Aids from the Japan Society for the Promotion of Science: [JSPS Fellowships; Grant Number 19J10653 to M.S., KAKENHI; Grant Number 18H02111 to Y.S. and Grant Number 16H06379 to A.M.], and by Core Research for Environmental Science and Technology (CREST) Scientific Research Grant No. JPMJCR15O3 (to Y.S. and A.M.) from the Japan Society for Technology (JST).

Acknowledgments: We thank Hiroyuki Ishida and Youshi Tazoe (Tohoku University) for their valuable discussion and comments, and we thank Louise Thiaville (Tohoku University) for her kind language support.

Conflicts of Interest: The authors declare no conflict of interest.

\section{Abbreviations}

$\begin{array}{ll}\text { CES } & \text { control by epistasy of synthesis } \\ \text { HI } & \text { high increase } \\ \text { MI } & \text { moderate increase } \\ \text { Pro }_{R B C S} & \text { the promoter of } R B C S \\ \text { Pro }_{R C A} & \text { the promoter of } R C A \\ \text { RBCL } & \text { large subunit of Rubisco } \\ \text { RBCS } & \text { small subunit of Rubisco } \\ \text { RCA } & \text { Rubisco activase } \\ \text { RuBP } & \text { Ribulose } 1,5 \text {-bisphosphate } \\ \text { SD } & \text { severe decrease } \\ \text { SE } & \text { standard error }\end{array}$

\section{References}

1. Evans, J.R. The relationship between carbon-dioxide-limited photosynthetic rate and ribulose-1,5-bisphosphate-carboxylase content in two nuclear-cytoplasm substitution lines of wheat, and the coordination of ribulose-bisphosphate-carboxylation and electron-transport. Planta 1986, 167, 351-358. [CrossRef] 
2. Makino, A.; Mae, T.; Ohira, K. Differences between wheat and rice in the enzymic properties of ribulose-1,5-bisphosphate carboxylase/oxygenase and the relationship to photosynthetic gas exchange. Planta 1988, 174, 30-38. [CrossRef]

3. Parry, M.A.J.; Andralojc, P.J.; Scales, J.C.; Salvucci, M.E.; Carmo-Silva, A.E.; Alonso, H.; Whitney, S.M. Rubisco activity and regulation as targets for crop improvement. J. Exp. Bot. 2013, 64, 717-730. [CrossRef]

4. Carmo-Silva, A.E.; Scales, J.C.; Madgwick, P.J.; Parry, M.A.J. Optimizing Rubisco and its regulation for greater resource use efficiency. Plant Cell Environ. 2015, 38, 1817-1832. [CrossRef] [PubMed]

5. Sharwood, R.E. Engineering chloroplasts to improve Rubisco catalysis: Prospects for translating improvements into food and fiber crops. New Phytol. 2017, 213, 494-510. [CrossRef] [PubMed]

6. Badger, M.R.; Lorimer, G.H. Interaction of sugar phosphates with the catalytic site of ribulose-1,5-bisphosphate carboxylase. Biochemistry 1981, 20, 2219-2225. [CrossRef] [PubMed]

7. Jordan, D.B.; Chollet, R. Inhibition of ribulose bisphosphate carboxylase by substrate ribulose 1,5-bisphosphate. J. Biol. Chem. 1983, 258, 13752-13758. [PubMed]

8. Parry, M.A.J.; Keys, A.J.; Madgwick, P.J.; Carmo-Silva, A.E.; Andralojc, P.J. Rubisco regulation: A role for inhibitors. J. Exp. Bot. 2008, 59, 1569-1580. [CrossRef]

9. Andralojc, P.J.; Madgwick, P.J.; Tao, Y.; Keys, A.; Ward, J.L.; Beale, M.H.; Loveland, J.E.; Jackson, P.J.; Willis, A.C.; Gutteridge, S.; et al. 2-Carboxy-D-arabinitol 1-phosphate (CA1P) phosphatase: Evidence for a wider role in plant Rubisco regulation. Biochem. J. 2012, 442, 733-742. [CrossRef]

10. Neuwald, A.F.; Aravind, L.; Spouge, J.L.; Koonin, E.V. AAA+: A class of chaperone-like ATPases associated with the assembly, operation, and disassembly of protein complexes. Genome Res. 1999, 9, $27-43$.

11. Portis, A.R. Rubisco activase - Rubisco's catalytic chaperone. Photosynth. Res. 2003, 75, 11-27. [CrossRef] [PubMed]

12. Portis, A.R.; Li, C.; Wang, D.; Salvucci, M.E. Regulation of Rubisco activase and its interaction with Rubisco. J. Exp. Bot. 2008, 59, 1597-1604. [CrossRef] [PubMed]

13. Bhat, J.Y.; Thieulin-Pardo, G.; Hartl, F.U.; Hayer-Hartl, M. Rubisco Activases: AAA+ chaperones adapted to enzyme repair. Front. Mol. Biosci. 2017, 4,1-10. [CrossRef] [PubMed]

14. Bracher, A.; Whitney, S.M.; Hartl, F.U.; Hayer-Hartl, M. Biogenesis and metabolic maintenance of Rubisco. Annu. Rev. Plant Biol. 2017, 68, 29-60. [CrossRef] [PubMed]

15. Zhang, Z.; Komatsu, S. Molecular cloning and characterization of cDNAs encoding two isoforms of ribulose-1,5-bisphosphate carboxylase/oxygenase activase in rice (Oryza sativa L.). 2000, 128, 383-389. [PubMed]

16. Zhang, N.; Portis, A.R. Mechanism of light regulation of Rubisco: A specific role for the larger Rubisco activase isoform involving reductive activation by thioredoxin-f. Proc. Natl. Acad. Sci. USA 1999, 96, 9438-9443. [CrossRef]

17. Zhang, N.; Kallis, R.P.; Ewy, R.G.; Portis, A.R. Light modulation of Rubisco in Arabidopsis requires a capacity for redox regulation of the larger Rubisco activase isoform. Proc. Natl. Acad. Sci. USA 2002, 99, 3330-3334. [CrossRef]

18. Wang, D.; Li, X.F.; Zhou, Z.J.; Feng, X.P.; Yang, W.J.; Jiang, D.A. Two Rubisco activase isoforms may play different roles in photosynthetic heat acclimation in the rice plant. Physiol. Plant. 2010, 139, 55-67. [CrossRef]

19. Chen, Y.; Wang, X.M.; Zhou, L.; He, Y.; Wang, D.; Qi, Y.H.; Jiang, D.A. Rubisco activase is also a multiple responder to abiotic stresses in rice. Plos One 2015, 10, 1-16. [CrossRef]

20. Mate, C.J.; Hudson, G.S.; von Caemmerer, S.; Evans, J.R.; Andrews, T.J. Reduction of ribulose biphosphate carboxylase activase levels in tobacco (Nicotiana tabacum) by antisense RNA reduces ribulose biphosphate carboxylase carbamylation and impairs photosynthesis. Plant Physiol. 1993, 102, 1119-1128. [CrossRef]

21. Mate, C.J.; von Caemmerer, S.; Evans, J.R.; Hudson, G.S.; Andrews, T.J. The relationship between $\mathrm{CO}_{2}$-assimilation rate, Rubisco carbamylation and Rubisco activase content in activase-deficient transgenic tobacco suggests a simple model of activase action. Planta 1996, 198, 604-613. [CrossRef] [PubMed]

22. Eckardt, N.A.; Snyder, W.; Portis, A.R.; Ogren, W.L. Growth and photosynthesis under high and low irradiance of Arabidopsis thaliana antisense mutants with reduced ribulose-1,5-bisphosphate carboxylase/oxygenase activase content. Plant Physiol. 1997, 113, 575-586. [CrossRef] [PubMed]

23. Hammond, E.T.; Andrews, T.J.; Mott, K.A.; Woodrow, I.E. Regulation of Rubisco activation is antisense plants of tobacco containing reduced levels of Rubisco activase. Plant J. 1998, 14, 101-110. [CrossRef] [PubMed] 
24. Jin, S.H.; Hong, J.; Li, X.Q.; Jiang, D.A. Antisense inhibition of Rubisco activase increases Rubisco content and alters the proportion of Rubisco activase in stroma and thylakoids in chloroplasts of rice leaves. Ann. Bot. 2006, 97, 739-744. [CrossRef] [PubMed]

25. Masumoto, C.; Fukayama, H.; Hatanaka, T.; Uchida, N. Photosynthetic characteristics of antisense transgenic rice expressing reduced levels of Rubisco activase. Plant Prod. Sci. 2012, 15, 174-182. [CrossRef]

26. Yamori, W.; Masumoto, C.; Fukayama, H.; Makino, A. Rubisco activase is a key regulator of non-steady-state photosynthesis at any leaf temperature and, to a lesser extent, of steady-state photosynthesis at high temperature. Plant J. 2012, 71, 871-880. [CrossRef]

27. Pearcy, R.W. Sunflecks and photosynthesis in plant canopies. Annu. Rev. Plant Physiol. Plant Mol. Biol. 1990, 41, 421-453. [CrossRef]

28. Taylor, S.H.; Long, S.P. Slow induction of photosynthesis on shade to sun transitions in wheat may cost at least $21 \%$ of productivity. Philos. Trans. R. Soc. B Biol. Sci. 2017, 372, 20160543. [CrossRef]

29. Crafts-Brandner, S.J.; Salvucci, M.E. Rubisco activase constrains the photosynthetic potential of leaves at high temperature and $\mathrm{CO}_{2}$. Proc. Natl. Acad. Sci. USA 2000, 97, 13430-13435. [CrossRef]

30. Perdomo, J.A.; Capó-Bauçà, S.; Carmo-Silva, A.E.; Galmés, J. Rubisco and Rubisco activase play an important role in the biochemical limitations of photosynthesis in rice, wheat, and maize under high temperature and water deficit. Front. Plant Sci. 2017, 8, 490. [CrossRef]

31. Fukayama, H.; Ueguchi, C.; Nishikawa, K.; Katoh, N.; Ishikawa, C.; Masumoto, C.; Hatanaka, T.; Misoo, S. Overexpression of Rubisco activase decreases the photosynthetic $\mathrm{CO}_{2}$ assimilation rate by reducing Rubisco content in rice leaves. Plant Cell Physiol. 2012, 53, 976-986. [CrossRef] [PubMed]

32. Fukayama, H.; Mizumoto, A.; Ueguchi, C.; Katsunuma, J.; Morita, R.; Sasayama, D.; Hatanaka, T.; Azuma, T. Expression level of Rubisco activase negatively correlates with Rubisco content in transgenic rice. Photosynth. Res. 2018, 137, 465-474. [CrossRef] [PubMed]

33. Yamori, W.; von Caemmerer, S. Effect of Rubisco activase deficiency on the temperature response of $\mathrm{CO}_{2}$ assimilation rate and Rubisco activation state: Insights from transgenic tobacco with reduced amounts of Rubisco activase. Plant Physiol. 2009, 151, 2073-2082. [CrossRef] [PubMed]

34. Yamaoka, C.; Suzuki, Y.; Makino, A. Differential expression of genes of the Calvin-Benson cycle and its related genes during leaf development in rice. Plant Cell Physiol. 2016, 57, 115-124. [CrossRef] [PubMed]

35. Takeuchi, A.; Yamaguchi, T.; Hidema, J.; Strid, A.; Kumagai, T. Changes in synthesis and degradation of Rubisco and LHCII with leaf age in rice (Oryza sativa L.) growing under supplementary UV-B radiation. Plant Cell Environ. 2002, 25, 695-706. [CrossRef]

36. Makino, A.; Osmond, B. Effects of nitrogen nutrition on nitrogen partitioning between chloroplasts and mitochondria in pea and wheat. Plant Physiol. 1991, 96, 355-362. [CrossRef]

37. Makino, A. Rubisco and nitrogen relationships in rice: Leaf photosynthesis and plant growth. Soil Sci. Plant Nutr. 2003, 49, 319-327. [CrossRef]

38. Evans, J.R. Photosynthesis and nitrogen relationship in leaves of $C_{3}$ plants. Oecologia 1989, 78, 9-19. [CrossRef]

39. Evans, J.R.; Terashima, I. Photosynthetic characteristics of spinach leaves grown with different nitrogen treatments. Plant Cell Physiol. 1988, 29, 157-165.

40. Makino, A.; Sakashita, H.; Hidema, J.; Mae, T.; Ojima, K.; Osmond, B. Distinctive responses of ribulose-1,5-bisphosphate carboxylase and carbonic anhydrase in wheat leaves to nitrogen nutrition and their possible relationships to $\mathrm{CO}_{2}$-transfer resistance. Plant Physiol. 1992, 100, 1737-1743. [CrossRef]

41. Vargas-Suárez, M.; Ayala-Ochoa, A.; Lozano-Franco, J.; García-Torres, I.; Díaz-Quiñonez, A.; Ortíz-Navarrete, V.F.; Sánchez-De-Jiménez, E. Rubisco activase chaperone activity is regulated by a post-translational mechanism in maize leaves. J. Exp. Bot. 2004, 55, 2533-2539. [CrossRef] [PubMed]

42. Makino, A.; Nakano, H.; Mae, T. Responses of ribulose-1,5-bisphosphate carboxylase, cytochrome $f$, and sucrose synthesis enzymes in rice leaves to leaf nitrogen and their relationships to photosynthesis. Plant Physiol. 1994, 105, 173-179. [CrossRef] [PubMed]

43. Makino, A.; Sato, T.; Nakano, H.; Mae, T. Leaf photosynthesis, plant growth and nitrogen allocation in rice under different irradiances. Planta 1997, 203, 390-398. [CrossRef]

44. Yamori, W.; Nagai, T.; Makino, A. The rate-limiting step for $\mathrm{CO}_{2}$ assimilation at different temperatures is influenced by the leaf nitrogen content in several $C_{3}$ crop species. Plant Cell Environ. 2011, 34, 764-777. [CrossRef] [PubMed] 
45. Suganami, M.; Suzuki, Y.; Sato, T.; Makino, A. Relationship between Rubisco activase and Rubisco contents in transgenic rice plants with overproduced or decreased Rubisco content. Soil Sci. Plant Nutr. 2018, 64, 352-359. [CrossRef]

46. Rodermel, S.; Haley, J.; Jiang, C.Z.; Tsai, C.H.; Bogorad, L. A mechanism for intergenomic integration: Abundance of ribulose bisphosphate carboxylase small-subunit protein influences the translation of the large-subunit mRNA. Proc. Natl. Acad. Sci. USA 1996, 93, 3881-3885. [CrossRef] [PubMed]

47. Wostrikoff, K.; Stern, D. Rubisco large-subunit translation is autoregulated in response to its assembly state in tobacco chloroplasts. Proc. Natl. Acad. Sci. USA 2007, 104, 6466-6471. [CrossRef]

48. Choquet, Y.; Vallon, O. Synthesis, assembly and degradation of thylakoid membrane proteins. Biochimie 2000, 82, 615-634. [CrossRef]

49. Suzuki, Y.; Makino, A. Availability of Rubisco small subunit up-regulates the transcript levels of large subunit for stoichiometric assembly of its holoenzyme in rice. Plant Physiol. 2012, 160, 533-540. [CrossRef]

50. Suzuki, Y.; Makino, A. Translational downregulation of $R B C L$ is operative in the coordinated expression of Rubisco genes in senescent leaves in rice. J. Exp. Bot. 2013, 64, 1145-1152. [CrossRef]

51. Suzuki, Y.; Ohkubo, M.; Hatakeyama, H.; Ohashi, K.; Yoshizawa, R.; Kojima, S.; Hayakawa, T.; Yamaya, T.; Mae, T.; Makino, A. Increased Rubisco content in transgenic rice transformed with the "sense" rbcS gene. Plant Cell Physiol. 2007, 48, 626-637. [CrossRef] [PubMed]

52. Makino, A.; Sage, R.F. Temperature response of photosynthesis in transgenic rice transformed with "sense" or "antisense" rbcS. Plant Cell Physiol. 2007, 48, 1472-1483. [CrossRef] [PubMed]

53. Suzuki, Y.; Miyamoto, T.; Yoshizawa, R.; Mae, T.; Makino, A. Rubisco content and photosynthesis of leaves at different positions in transgenic rice with an overexpression of RBCS. Plant Cell Env. 2009, 32, 417-427. [CrossRef] [PubMed]

54. Kawahara, Y.; de la Bastide, M.; Hamilton, J.P.; Kanamori, H.; McCombie, W.R.; Ouyang, S.; Schwartz, D.C.; Tanaka, T.; Wu, J.; Zhou, S.; et al. Improvement of the Oryza sativa Nipponbare reference genome using next generation sequence and optical map data. Rice 2013, 6, 4. [CrossRef] [PubMed]

55. Kyozuka, J.; McElroy, D.; Hayakawa, T.; Xie, Y.; Wu, R.; Shimamoto, K. Light-regulated and cell-specific expression of tomato $r b c S-g u s A$ and rice $r b c S-g u s A$ fusion genes in transgenic rice. Plant Physiol. 1993, 102, 991-1000. [CrossRef] [PubMed]

56. Toki, S.; Hara, N.; Ono, K.; Onodera, H.; Tagiri, A.; Oka, S.; Tanaka, H. Early infection of scutellum tissue with Agrobacterium allows high-speed transformation of rice. Plant J. 2006, 47, 969-976. [CrossRef] [PubMed]

57. Suzuki, Y.; Kondo, E.; Makino, A. Effects of co-overexpression of the genes of Rubisco and transketolase on photosynthesis in rice. Photosynth. Res. 2017, 131, 281-289. [CrossRef]

58. Von Caemmerer, S.; Farquhar, G.D. Some relationships between the biochemistry of photosynthesis and the gas exchange of leaves. Planta 1981, 153, 376-387. [CrossRef]

59. Makino, A.; Mae, T.; Ohira, K. Enzymic properties of ribulose-1,5-bisphosphate carboxylase/oxygenase purified from rice leaves. Plant Physiol. 1985, 79, 57-61. [CrossRef]

60. Makino, A.; Nakano, H.; Mae, T. Effects of growth temperature on the responses of ribulose-1,5-biphosphate carboxylase, electron transport components, and sucrose synthesis enzymes to leaf nitrogen in rice, and their relationships to photosynthesis. Plant Physiol. 1994, 105, 1231-1238. [CrossRef]

61. Suzuki, Y.; Kawazu, T.; Koyama, H. RNA isolation from siliques, dry seeds, and other tissues of Arabidopsis thaliana. Biotechniques 2004, 37, 542-544. [CrossRef] [PubMed]

62. Ogawa, S.; Suzuki, Y.; Yoshizawa, R.; Kanno, K.; Makino, A. Effect of individual suppression of RBCS multigene family on Rubisco contents in rice leaves. Plant Cell Env. 2012, 35, 546-553. [CrossRef] [PubMed]

(C) 2020 by the authors. Licensee MDPI, Basel, Switzerland. This article is an open access article distributed under the terms and conditions of the Creative Commons Attribution (CC BY) license (http://creativecommons.org/licenses/by/4.0/). 